\title{
The deficiency of CX3CL1/CX3CR1 system ameliorates high fructose diet-induced kidney injury by regulating NF-kB pathways in CX3CR1-knock out mice
}

\author{
YONG-WU YU*, MING-XU LI*, ZHI-YONG ZHANG and HAI YU \\ Department of Nephrology, Navy General Hospital of Chinese PLA, Beijing 100048, P.R. China
}

Received January 26, 2016; Accepted January 12, 2018

DOI: $10.3892 /$ ijmm.2018.3573

\begin{abstract}
Fructose, the most important functional food additive from the last century, has been widely used in industry, agriculture, light industry, food and medicine. With the improvement of people's living standard and economic level, excess intake of fructose results in metabolic symptoms, including hyperleptinemia, insulin resistance and neuroinflammation is causing high risk of chronic kidney disease development in humans and animals. However, the underlying molecular mechanism of renal injury is still not fully understood, and the development of effective drugs and treatments are delayed. Hence, we investigated the role of crosstalk of CX3CL1-CX3CR1 axis and nuclear factor- $\kappa \mathrm{B}(\mathrm{NF}-\kappa \mathrm{B})$ signaling pathway in the development of renal injury. CX3CL1-knock-out C57BL/6 mice were constructed and used to analyze the influence of CX3CL1-related signaling pathways on kidney injury of wild-type (WT) mice and CXECR1 deficiency mice, which were administrated with $30 \%$ fructose water. Western blotting, quantitative RT-PCR (qRT-PCR), immunohistochemistry, ELISA, flow cytometry and biochemical indicator analysis were used to determine the levels of renal injury and key signaling pathway associated with renal damage. The results indicated that administration of high fructose intake can cause typical renal inflammatory responses in serum and tissues. Fructose enhances the CX3CL1-CX3CR1 axis and NF- $\kappa \mathrm{B}$ activation, and promotes crosstalk of CX3CL1-CX3CR1 and $\mathrm{NF}-\kappa \mathrm{B}$ pathways. The phosphorylated AKT could be significantly activated in fructose-induced renal injury via CX3CL1-CX3CR1 axis. CX3CR1 expression between WT and $\mathrm{CX} 3 \mathrm{CR}^{-1-}$ mice were evaluated to establish their relationship with injury. Our results indicated that CX3CR1 may be
\end{abstract}

Correspondence to: Dr Yong-Wu Yu, Department of Nephrology, Navy General Hospital of Chinese PLA, Beijing 100048, P.R. China E-mail: yuyongwu100048@sina.com

*Contributed equally

Key words: kidney injury, CX3CL1-CX3CR1 axis, nuclear factor- $\kappa \mathrm{B}$, inflammation, $\mathrm{CX} 3 \mathrm{CR} 1$ deficiency the central and major indicator in the process of renal injury, which mediate AKT pathway and further enhance the NF- $\kappa \mathrm{B}$ activation. These findings demonstrated that crosstalk of CX3CL1-CX3CR1 axis and NF- $\mathrm{B}$ signaling pathway play a direct role in fructose-induced kidney injury. Inhibition of CX3CL1-CX3CR1 pathway may suppress renal-related diseases. It may be a potential treatment choice for the clinical diagnoses and treatment in the future.

\section{Introduction}

Heterogeneous disorders affecting kidney structure and function, chronic kidney disease has been treated as a threat to the health of the people all over the world (1). Due to the recurrent hospitalization, accelerated death and morbidity, increasing research has been devoted to investigate the underlying molecular mechanism. As the final manifestation of chronic kidney disease, renal fibrosis is the common pathway for chronic kidney disease towards kidney failure $(2,3)$. It is characterized by an excessive accumulation and deposition of extracellular matrix components. Fibrosis formation could be stimulated by chronic glomerulonephritis, chronic pyelonephritis, obstructive nephropathy, systemic lupus; hereditary kidney disease, diabetic nephropathy, hypertensive kidney disease, drug-induced kidney disease, hepatitis B or the HIV caused kidney disease and renal transplantation (4-7). Among these inducements, with the development of economy and the improvement of people's living standard, eating habits caused kidney disease has been widely received attention by scholars. In previous reports, diet-induced increase in plasma oxidized LDL could promote early fibrosis in a renal porcine auto-transplantation model $(8,9)$. Moreover, high fat diet-induced obesity would change kidney-related gene expression and lead to chronic kidney disease formation $(10,11)$. These changes alter normal physiological activity and promote type II diabetes, in turn; diabetes enhancement will increase kidney injury development and fibrosis formation (12). However, though the medical substantial progress has expanded our knowledge of kidney related diseases, there has been little in the way of new therapies. Hence, the additional intervention, including treatment with chemoprevention from natural products, for the treatment of kidney injury. 
To our knowledge, in the development of kidney inflammation, TGF- $\beta 1 /$ Smads pathway has been regarded as the most significant in the promotion for fibrosis formation and kidney injury (13). High fat diet-induced kidney damage also has been thought to be associated with inflammation development. As previously reports, kidney injury as a typical inflammatory response, nuclear factor $-\kappa \mathrm{B}(\mathrm{NF}-\kappa \mathrm{B})$ signaling pathway was directly involved in the developmental process of lung injury $(14,15)$. Thus, how to inhibit the activation of NF- $\kappa B$ pathway may be the key point for the treatment of renal inflammation. CX3CL1-CX3CR1 interaction has been indicated as important in many inflammation-related disorder, including hepatitis and fibrosis, nerve damage and tumors $(16,17)$. CX3CL1-CX3CR1 axis has the ability to enhance the levels of phosphorylated NF- $\mathrm{B}$, which in turn, could continually upregulate CX3CL1-CX3CR1 interaction. Crosstalk of CX3CL1-CX3CR1 axis and NF- $\kappa \mathrm{B}$ pathways play a critical role in the inflammatory formation and development $(15,17)$. Hence, we investigated whether CX3CR1 knock out inhibits high fructose-stimulated acute kidney injury by interfering with CX3CL1-CX3CR1 axis expression and $\mathrm{NF}-\kappa \mathrm{B}$ pathways activation. Furthermore, podocyte cells were used as a model to evaluate the effects of CX3CR1 on inflammatory responses.

\section{Materials and methods}

Reagents and animals. Fructose (CAS: 53188-23-1, HPLC analysis $\geq 99 \%$ ) was purchased from the National Institute for the Control of Pharmaceutical and Biological Products (Beijing, China). Interleukin-1 $\beta$ (IL-1 $\beta$ ) (freeze-dried powder) was obtained from Nanjing Biohelper Co., Ltd. (Nanjing, China) and prepared in phosphate-buffered saline (PBS) at the concentration of $100 \mu \mathrm{g} / \mathrm{ml}$. The antibodies used in this study were obtained from CST Technology Co. (Danvers, MA, USA). The mouse enzyme-linked immunosorbent assay (ELISA) kits were purchased from BioLegend (San Diego, CA, USA). Male C57BL/6 mice with CX3CR1 gene-knock out were purchased from Beijing Biocytogen Co., Ltd. (Beijing, China). The mice weighting 20-25 g were housed in a temperature and humidity-controlled environment $\left(25 \pm 2{ }^{\circ} \mathrm{C}, 50 \pm 10 \%\right.$ humidity) with a standard $12 \mathrm{~h}$ light/dark cycle with food and water. This study was approved by the Ethics Committee on Animal Research at Department of Nephrology, Navy General Hospital of Chinese PLA. The mice were randomly divided into 3 groups: i) wild-type (WT); ii) Fructose-fed wild-type (Fru-WT); iii) Fructose-fed CX3CR1-knock out mice (Fru-CX3CR1-KO). Fru-WT and Fru-CX3CR1-KO group mice were orally administered with $30 \%$ fructose water/ day; and the WT mice were orally fed with equal amount of PBS. The entire experimental period was 56 days. All animal experiments were performed in accordance with the guide for the Care and Use of Laboratory Animals established by the US National Institutes of Health.

Cell culture. The conditionally immortalized mouse podocyte cell line was obtained from Institute of Biochemistry and Cell Biology, SIBS, CAS (Shanghai, China). Cells were grown and maintained at $33^{\circ} \mathrm{C}$ in RPMI-1640 medium containing $10 \%$ fetal bovine serum (FBS), recombinant interferon- $\gamma$ (R\&D Systems, Minneapolis, MN, USA) and $1 \%$ penicillin/streptomycin. Recombinant lent viral particles encoding CX3CR1 and short hairpin RNA targeting CX3CR1 were produced, concentrated, and titrated. The short hairpin RNA oligonucleotide sequences of CX3CR1 were described earlier (18). Cells were seeded at $3 \times 10^{4}$ cells $/ \mathrm{ml}$ and were infected with recombinant lent virus twice with an interval of $12 \mathrm{~h}$ and incubated for $24 \mathrm{~h}$. After $24 \mathrm{~h}$, the medium was refreshed and the cells were cultured for another $24 \mathrm{~h}$. Cells were serum starved for $36 \mathrm{~h}$ and stimulated with IL-1 $\beta$ $(75 \mathrm{ng} / \mathrm{ml})$ for the indicated time periods.

Biochemical analysis. At the end of all experiments, rats were sacrificed by decapitation at 9:30-10:30 a.m. after a 16-h fast in order to avoid the fluctuation of hormone levels due to circadian rhythms. Before this, the insulin tolerance test (ITT) and oral glucose tolerance test (OGTT) were performed in accordance with a perviously described method (20).

Inflammatory cell counts of kidney tissue. The kidney samples were centrifuged $\left(4^{\circ} \mathrm{C}, 3,000 \mathrm{rpm}\right.$ for $\left.10 \mathrm{~min}\right)$ to pellet the cells. The cell pellets were resuspended in PBS for the total cell counts using a hemacytometer, and cytospins were prepared for differential cell counts by staining with the Wright-Giemsa staining method.

Histopathological examination of kidney tissues and flow cytometry analysis. Histopathological evaluation was performed by Nanjing Biohelper Co., Ltd. (Nanjing, China). Kidneys were fixed with $10 \%$ buffered formalin, imbedded in paraffin, and sliced. After hematoxylin and eosin (H\&E) staining, Red Oil O, Masson and EM pathological changes of tissues were observed under a light microscope or electron microscope. Some samples were subjected to immunohistochemical staining (CX3CL1, CX3CR1 and $\mathrm{NF}-\kappa \mathrm{B})$ according to CST technology Co. introduction and performed by Shanghai Zhenda Biotechnology, Co., Ltd. (Shanghai, China). For flow cytometry analysis, the cells were obtained through shearing kidney tissue, separating by collagenase type II (Invitrogen, Carlsbad, CA, USA) digestion and suspended in RPMI-1640 medium (Gibco-BRL, Grand Island, NY, USA). Cell suspensions were centrifuged at 1,000 rpm for $5 \mathrm{~min}$ to remove cellular debris and impurities. Then, the entire cells were harvested and washed twice in Hank's buffer (Gibco-BRL). According to the protocol of R\&D kit systems (R\&D Systems) for flow cytometry, add anti-CD45 FITC and anti-CD80 FITC antibody to the flow cytometry tube containing single-cell suspension, and these tubes were analyzed by Cytomics ${ }^{\mathrm{TM}}$ FC 500 MCL of Beckman Coulter (Brea, CA, USA).

ELISA measurement and biochemical analysis. At the end of the experiments, blood were extracted from the eyeball, the different serum concentration of the inflammatory cytokines such as tumor necrosis factor- $\alpha$ (TNF- $\alpha$ ), interferon- $\gamma$ (IFN- $\gamma$ ), IL-2, IL-1 $\beta$ and IL-6 were measured using ELISA kits according to the manufacturer's instructions (R\&D Systems). The other indicators shown in Table I were also performed by Shanghai Zhenda Biotechnology, Co., Ltd. 
Table I. Effects of fructose on physiological indexes and biochemical parameters in serum of CX3CR1-KO mice.

\begin{tabular}{|c|c|c|c|}
\hline Items & WT & Fru-WT & Fru-CX3CR1-KO \\
\hline Serum uric acid (mg/dl) & $3.28 \pm 70.79$ & $6.91 \pm 71.50^{\mathrm{a}}$ & $4.73 \pm 70.19^{d}$ \\
\hline Urinary uric acid (mg/dl) & $41.77 \pm 71.52$ & $32.15 \pm 73.79^{b}$ & $40.70 \pm 72.34^{\mathrm{e}}$ \\
\hline Serum creatinine (mg/dl) & $0.96 \pm 70.24$ & $1.94 \pm 70.26^{\mathrm{c}}$ & $0.84 \pm 71.18^{\mathrm{e}}$ \\
\hline Urinary creatinine (mg/dl) & $37.53 \pm 72.89$ & $27.41 \pm 73.76^{\mathrm{a}}$ & $34.97 \pm 71.96^{\mathrm{d}}$ \\
\hline Blood urea nitrogen (mg/dl) & $32.95 \pm 71.61$ & $42.47 \pm 72.74^{\mathrm{a}}$ & $32.93 \pm 74.38^{\mathrm{d}}$ \\
\hline FEUA $(\%)$ & $19.17 \pm 70.34$ & $12.37 \pm 70.25^{\mathrm{b}}$ & $16.85 \pm 71.30^{\mathrm{e}}$ \\
\hline Serum triglyceride $(\mathrm{mg} / \mathrm{dl})$ & $119.84 \pm 5.68$ & $175.30 \pm 4.58^{\mathrm{a}}$ & $125.17 \pm 6.96^{\mathrm{d}}$ \\
\hline Serum total cholesterol (mg/dl) & $72.09 \pm 1.21$ & $85.36 \pm 1.87^{\mathrm{a}}$ & $72.80 \pm 1.21^{\mathrm{d}}$ \\
\hline Serum very-low density lipoprotein $(\mu \mathrm{g} / \mathrm{ml})$ & $93.42 \pm 4.98$ & $137.97 \pm 6.62^{\mathrm{c}}$ & $95.98 \pm 6.56^{\mathrm{d}}$ \\
\hline Serum insulin $(\mu \mathrm{g} / \mathrm{ml})$ & $2.33 \pm 0.19$ & $3.90 \pm 0.46^{\mathrm{c}}$ & $2.02 \pm 0.23^{\mathrm{d}}$ \\
\hline Serum leptin $(\mu \mathrm{g} / \mathrm{l})$ & $0.48 \pm 0.02$ & $0.64 \pm 0.03^{\mathrm{a}}$ & $0.46 \pm 0.05^{\mathrm{e}}$ \\
\hline
\end{tabular}

These results are expressed as mean $\pm \mathrm{SEM}, \mathrm{n}=7$. ${ }^{\mathrm{a}} \mathrm{P}<0.01$ compared with WT group; ${ }^{\mathrm{C}}<0.001$ compared with WT group; ${ }^{\mathrm{d}} \mathrm{P}<0.01$ compared with fructose-fed group; ${ }^{\mathrm{e}} \mathrm{P}<0.05$ compared with fructose-fed group; ${ }^{\mathrm{f}} \mathrm{P}<0.001$ compared with fructose-fed group. WT, wild-type; Fru-WT, Fructose-fed wild-type.

Western blotting and quantitative RT-PCR (qRT-PCR) analysis. Proteins were extracted from the kidney using T-PER Tissue Protein Extraction Reagent kit (Thermo Fisher Scientific, Waltham, MA, USA) according to the manufacturer's instructions. Protein concentrations were determined by BCA protein assay kit, and equal amounts of protein were loaded per well on a $10 \%$ sodium dodecyl sulphatepolyacrylamide gel. Subsequently, proteins were transferred onto polyvinylidene difluoride membrane. The resulting membrane was blocked with Tris-buffered saline containing $0.05 \%$ Tween-20 (TBS-T), supplemented with 5\% skim milk (Sigma, St. Louis, MO, USA) at room temperature for $2 \mathrm{~h}$ on a rotary shaker, and followed by TBS-T washing. The specific primary antibody, diluted in TBST, was incubated with the membrane at $4^{\circ} \mathrm{C}$ overnight. Subsequently, the membrane was washed with TBS-T followed by incubation with the peroxidase-conjugated secondary antibody at room temperature for $1 \mathrm{~h}$. The immunoactive proteins were detected by using an enhanced chemiluminescence western blotting detection kit. Western blot bands were observed using GE Healthcare ECL western blotting analysis system and exposed to Kodak X-ray film. For qRT-PCR experiments, quantitative RT-PCR (qRT-PCR) and western blot analysis were performed as described previously (17).

Statistical analysis. Data are expressed as means \pm SEM. Treated cells, tissues and the corresponding controls were compared using GraphPad Prism (version 6.0; GraphPad Software, Inc., La Jolla, CA, USA) by one-way ANOVA with Dunn's least significant difference tests. Differences between groups were considered significant at $\mathrm{p}<0.05$.

\section{Results}

CX3CRl deficiency ameliorates high fructose-induced metabolic disorder responses and inflammatory cell counts. We investigated that the effect of CX3CR1 deficiency mice on fructose-stimulated kidney injury. As shown in Table I, major kidney injury-related indicators in serum such as uric acid, blood urea nitrogen and serum total cholesterol, were significantly increased with the fructose administration, compared to WT group. In contrast, in CX3CR1-KO with fructose treatment mice, these were downregulated, compared with the model. Also, as shown in Fig. 1A and B, the serum glucose levels tested by ITT and OGTT were increased in WT+Fru group, compared with CX3CR1-KO. Thus, high fructose is capable of changing metabolic activities and weaken renal function. Fig. 1C shows that inflammation-related cytokines in WT+Fru were significantly upregulated with the increase of treatment in a time-independent manner. Of note, The data of Fig. 2A-E indicated that CX3CR1-KO may suppress the inflammation-related cells in kidneys, including neutrophils and macrophages caused by fructose administration-induced renal injury. These basic biomarkers suggested that CX3CR1 deficiency is capable of suppressing kidney damage with fructose administration.

Influence of CX3CR1 deficiency on inflammation-related cytokines expression in fructose-induced kidney injury. As indicated in Fig. 2F-N, the fructose administration significantly enhance renal injury levels compared to PBS group. Moreover, $\mathrm{CX} 3 \mathrm{CR}^{-/}$mice had a lower inflammatory cytokine expression than fructose-fed WT mice. We further investigated the mRNA level expression of inflammatory cytokines. Data in Fig. 3A illustrate that the administration of fructose can increase inflammatory cytokine expression in mRNA level, and downregulate in CX3CR1 deficiency mice. Fig. 3B shows that fructose significantly enhance the ratio of CD45 and CD80 positive cells. In contrast, in CX3CR1-KO mice a lower ratio of positive cells in CD45 and CD80 than fructose-fed WT was seen. The histopathologic examination of kidney tissues in Fig. 3C show the effects of fructose on renal injury. The results indicated that fructose caused lipid accumulation, inflammatory cell infiltration, a certain degree of fibrosis and damage of the tissues structure. 

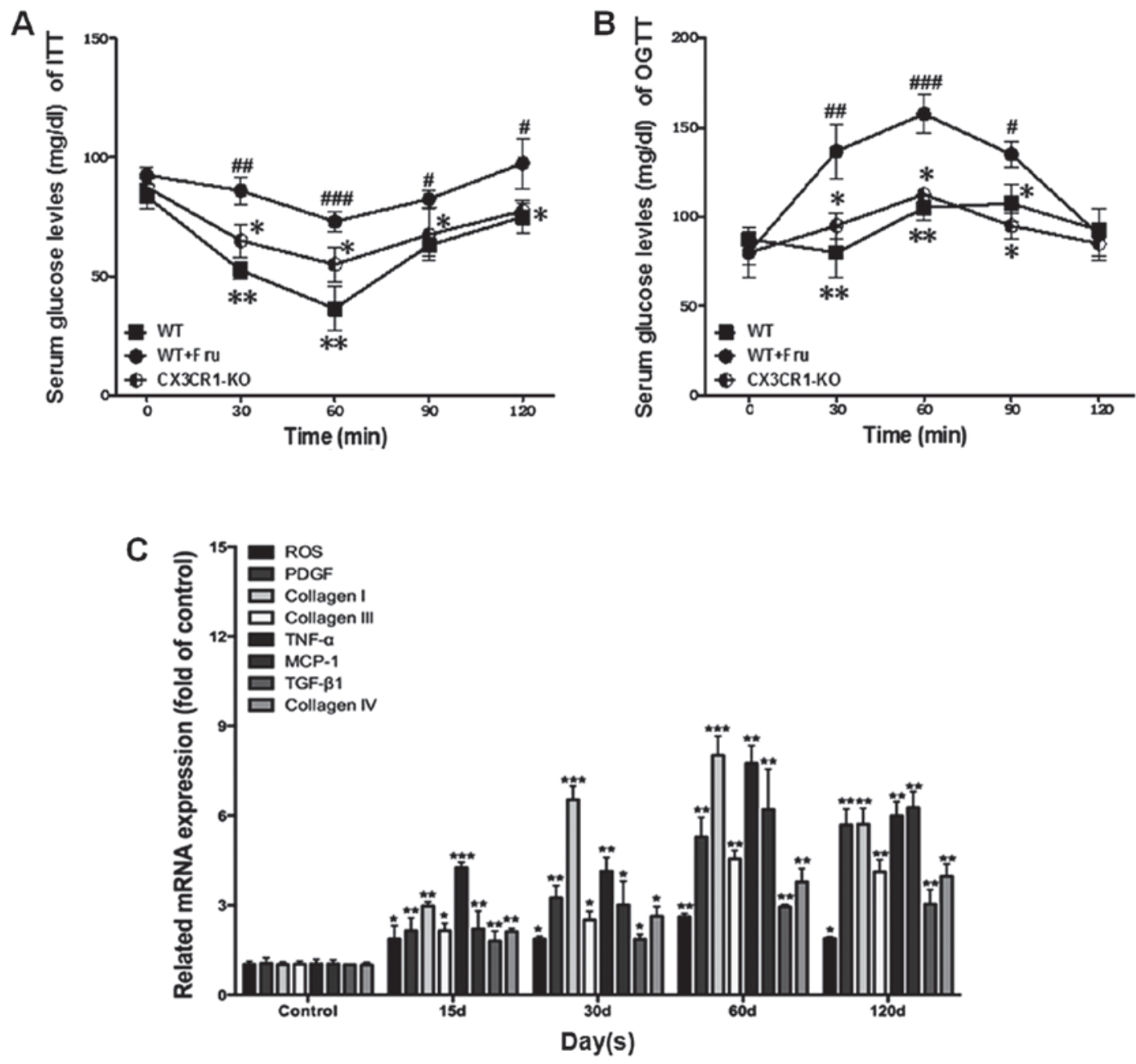

Figure 1. CX3CR1 deficiency affects metabolism and kidney function in fructose-fed mice. (A) Insulin tolerance test of rats. (B) Oral glucose tolerance test of rats. (C) Real-time quantitative PCR analysis of renal fibrosis related gene expression in different experimental periods. Data are expressed as the mean \pm SEM. ${ }^{+} \mathrm{P}<0.05,{ }^{++} \mathrm{P}<0.01$ and ${ }^{+++} \mathrm{P}<0.001$ vs. WT; ${ }^{\#} \mathrm{P}<0.05,{ }^{\# \#} \mathrm{P}<0.01$ and ${ }^{\# \# \prime} \mathrm{P}<0.001$ vs. Fructose (Fru); ns, no significances.

Effects of CX3CR1-KO on CX3CL1/CX3CR1 axis-stimulated $N F-\kappa B$ signaling pathway. As showed in Fig. 4A, the IHC analysis given the AKT and NF- $\kappa$ B pathways were significantly activated with the administration of fructose. Also, in $\mathrm{CX} 3 \mathrm{CR}^{-1 /}$ mice, the phosphorylation of NF- $\mathrm{kB}$ is lower than it in WT group. In addition, the western blot data (Fig. 4B) showed that AKT-stimulated NF- $\kappa \mathrm{B}$ signaling pathway in CX3CR $1^{-1-}$ mice with a significant difference compared with WT. These findings demonstrated that AKT pathway could be a link in the development of fructose-induced inflammation of renal injury, which was directly activated by CX3CL1-CX3CR 1 axis. The AKT-stimulated NF- $\kappa B$ signaling pathway activation was downregulated when the $\mathrm{CX} 3 \mathrm{CR} 1^{-/}$mice were challenged with fructose administration.

CX3CR1 deficiency inhibits inflammatory response through $N F-\kappa B$ pathway in podocyte cells. Research has demonstrated that the activation of the NF- $\mathrm{KB}$ pathway is involved in inflammation-related diseases both in experimental models and in humans. Moreover, CX3CL1-CX3CR1 axis has been shown to regulate the NF- $\mathrm{\kappa B}$ pathway in multiple cell systems. Hence, we investigated the effect of CX3CL1-CX3CR1 axis on NF- $\kappa \mathrm{B}$ pathway and the induced inflammatory responses with fructose administration. As showed in Fig. 5A, B and D, the $\mathrm{I} \kappa \mathrm{B} \alpha$ degradation level was significantly upregulated in CX3CR1 deficiency, compared with WT mice. The increase of I $\mathrm{KB} \alpha$ phosphorylation level results in the upregulation of NF- $\kappa B$ pathway activation, compared to CX3CR1 deficiency mice. The activity of NF- $\mathrm{KB}$ is also downregulated in the deficiency mice. Of note, in podocyte cells with CX3CR1 deficiency, the inflammatory cytokines have a lower release levels than WT group (Fig. 5C). Thus, these findings demonstrated that CX3CR1 deficiency has a key role in the inhibitory effect of fructose-induced inflammatory responses.

\section{Discussion}

Kidney injury syndrome consisting of chronic inflammatory responses, has been emphasized as a serious health threat world-wide $(1,19)$. Moreover, as a serious syndrome, the formation and development of kidney diseases are associated with high morbidity and mortality. It is characterized by an excessive accumulation and deposition of extracellular matrix components. Kidney injury formation could be stimulated by chronic glomerulonephritis, chronic pyelonephritis, obstructive nephropathy, systemic lupus; hereditary kidney disease, 

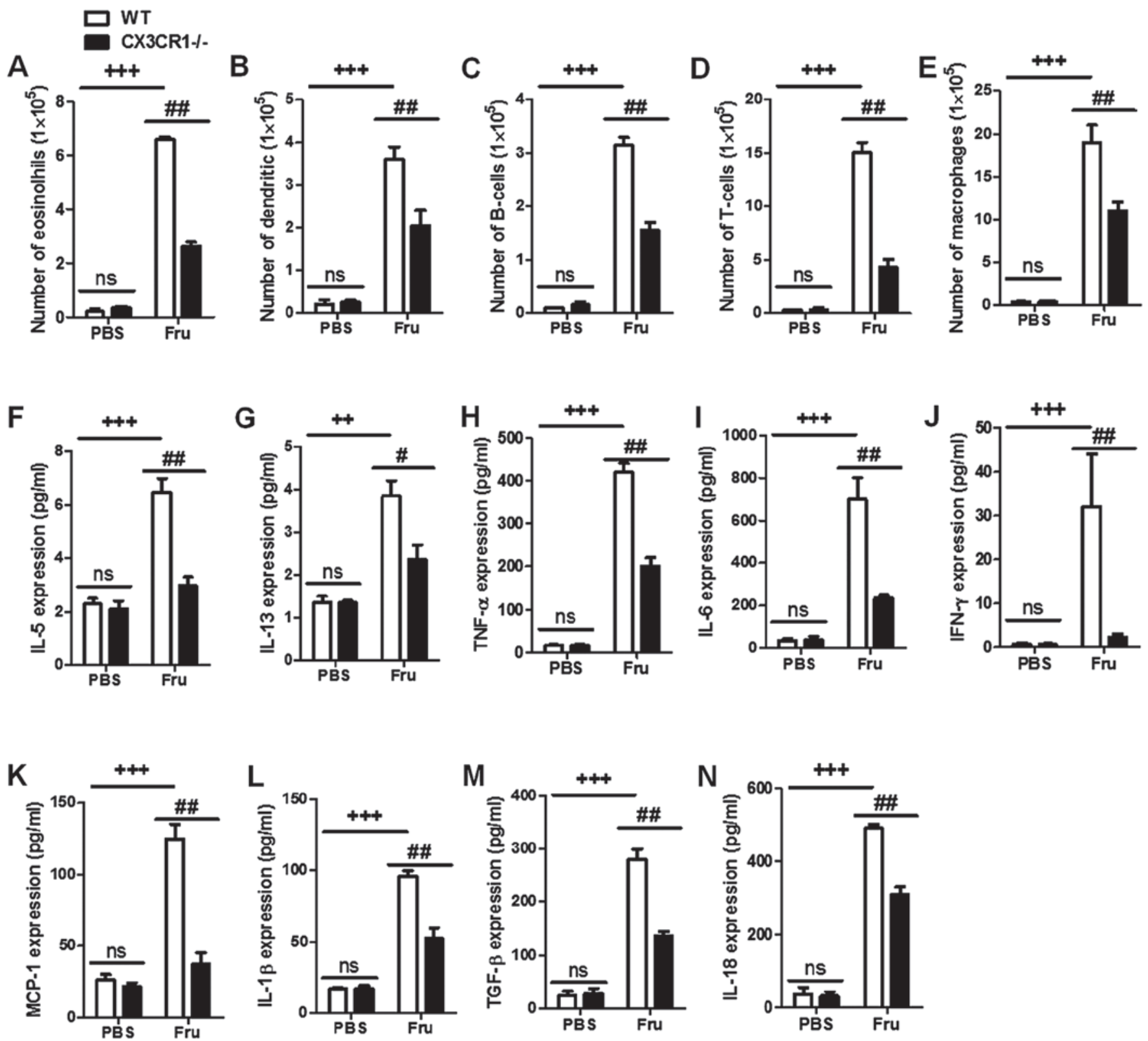

Figure 2. CX3CR1 deficiency ameliorates high fructose-induced metabolic disorder responses and inflammatory cell counts. (A-E) The inflammation-related cells counts in fructose-induced renal tissues. (F-N) Enzyme-linked immunosorbent assay (ELISA) analysis was used to show the inflammatory cytokine expression in fructose-induced kidney injury. Data are expressed as the mean $\pm \mathrm{SEM} .{ }^{+} \mathrm{P}<0.05,{ }^{++} \mathrm{P}<0.01$ and ${ }^{+++} \mathrm{P}<0.001 \mathrm{vs}$. WT; ${ }^{*} \mathrm{P}<0.05$, ${ }^{\# \#} \mathrm{P}<0.01$ and

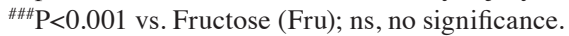

diabetic nephropathy, hypertensive kidney disease, druginduced kidney disease, hepatitis B or the HIV caused kidney disease and renal transplantation. However, the molecular mechanism of high fructose intake-induced chronic kidney disease, even kidney fibrosis is not absolutely explained and reported. In previous studies, renal damage as a typical inflammatory response, $\mathrm{NF}-\kappa \mathrm{B}$ signaling pathway was directly involved in the developmental process of injury $(19,20)$. Thus, how to inhibit the activation of $\mathrm{NF}-\kappa \mathrm{B}$ pathway may be the key point for the treatment of renal damage. CX3CL1-CX3CR1 interaction has been treated as important in inflammationrelated disorders, including hepatitis and fibrosis, nerve damage and tumor (21). CX3CL1-CX3CR1 axis has the ability to enhance the levels of phosphorylated $\mathrm{NF}-\kappa \mathrm{B}$; in turn, $\mathrm{NF}-\kappa \mathrm{B}$ activation could continually upregulate CX3CL1-
CX3CR1 interaction (17,18). Crosstalk of CX3CL1-CX3CR1 axis and NF- $\kappa \mathrm{B}$ pathways play a critical role in the inflammation and development (17). Hence, we investigated whether CX3CR1-KO inhibits fructose-stimulated kidney injury by interfering CX3CL1-CX3CR1 axis expression and NF- $\kappa \mathrm{B}$ pathways activation.

We used C57BL/6 mice to construct fructose-induced renal injury model in order to investigate the effects of CX3CL1CX3CR1 axis. The results of our data indicated that fructose administration could cause inflammatory cytokine releases including TNF- $\alpha$, IL-1 $\beta$, IL-6, TGF- $\beta$ and IL-18 in serum. Moreover, the inflammatory cell counts of fructose-induced renal tissues were significantly enhanced. Furthermore, we tested the crucial role of CX3CL1/CX3CR1 signaling pathway in fructose-induced kidney injury. The results showed that 

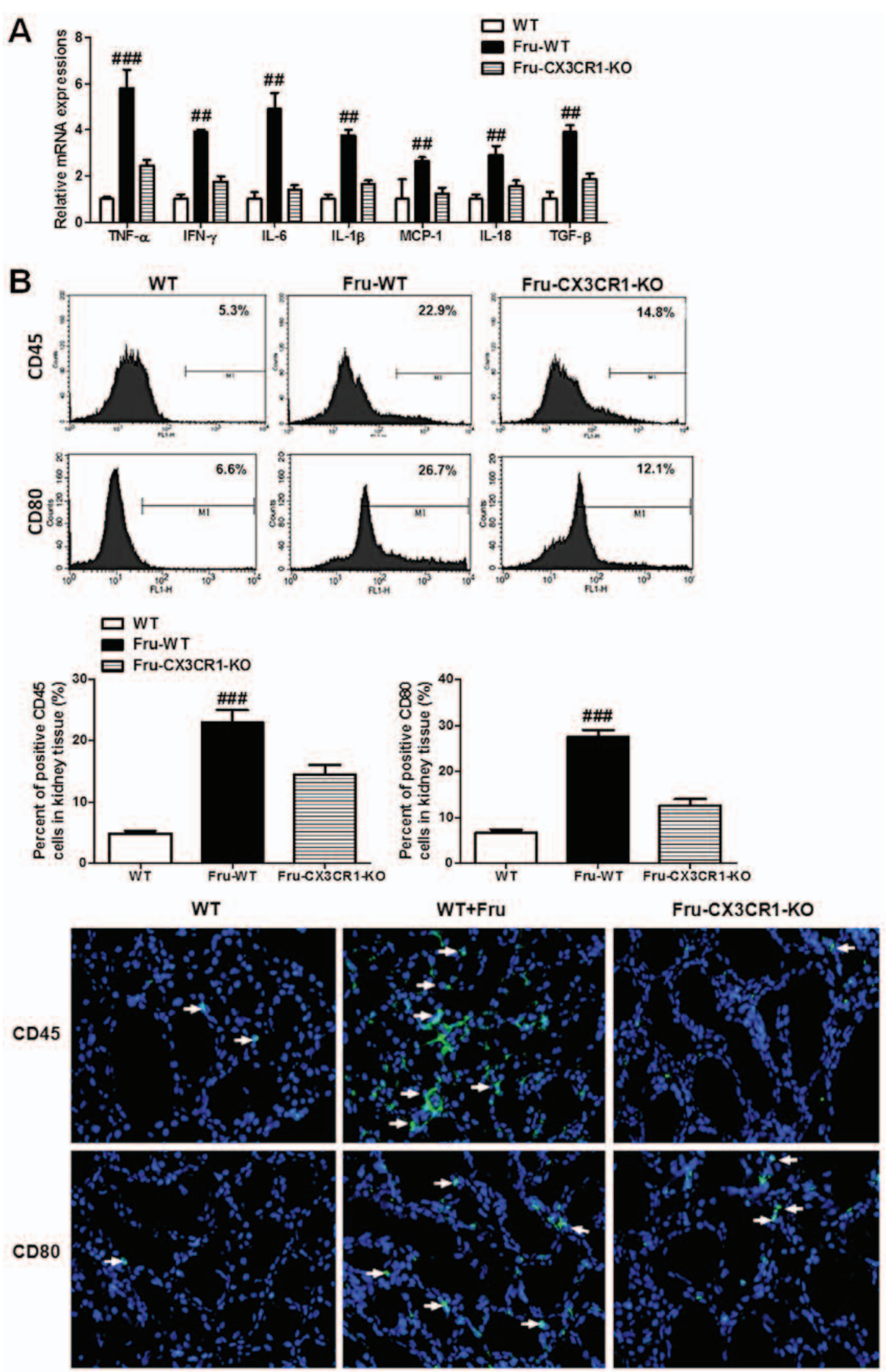

Figure 3. Influence of CX3CR1 deficiency on inflammation-related cytokine expression in fructose-induced kidney injury. (A) Quantitative RT-PCR analysis showed the inflammatory cytokines in mRNA expression. (B) Flow cytometry analysis showed the major maker expression of renal injury-CD45 and CD80 in fructose-induced WT mice and CX3CR1-KO mice. Data are expressed as the mean \pm SEM. ${ }^{\#} \mathrm{P}<0.05,{ }^{\# \#} \mathrm{P}<0.01$ and ${ }^{\# \# \#} \mathrm{P}<0.001$ vs. WT; ${ }^{*} \mathrm{P}<0.05$, ${ }^{* *} \mathrm{P}<0.01$ and ${ }^{* * * *} \mathrm{P}<0.001$ vs. Fru-WT.

CX3CL1/CX3CR1 axis is involved in the process of renal damage and could be activated via fructose administration.
The activation of CX3CL1/CX3CR1 axis will further enhance the NF- $\mathrm{kB}$ pathway phosphorylation levels. As previous 
A

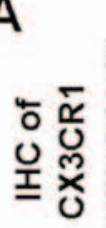

WT
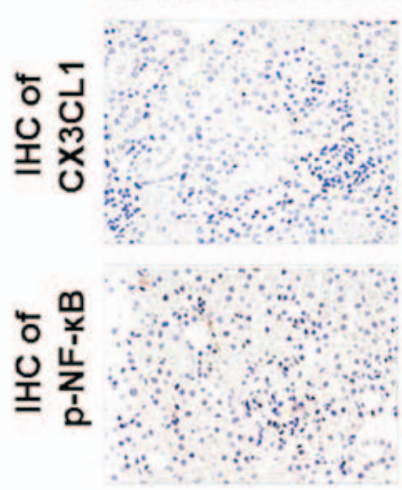

Fru-WT
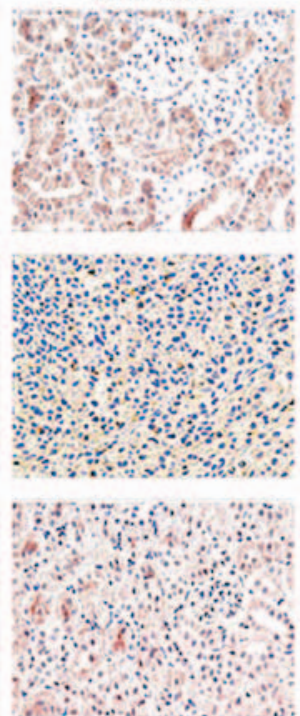

Fru-CX3CR1-KO
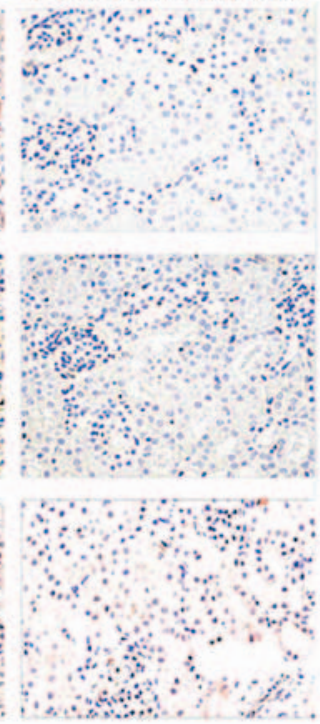

B

B

Fru WT CX3CR1-\%

p-AKT

AKT

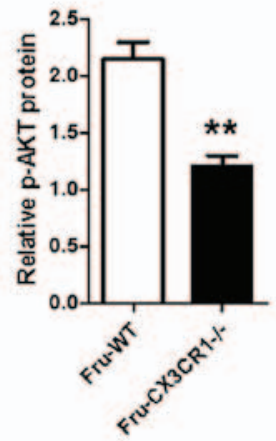

Fru

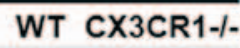

p-IKBa

IKBa

WT CX3CR1\%-
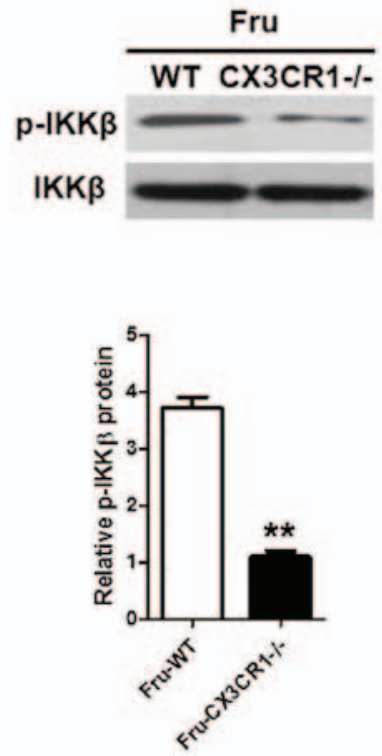

Fru

WT CX3CR1-\%

p-NF-kB

NF-KB

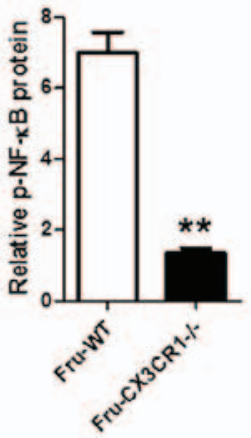

Figure 4. Effects of CX3CR1 deficiency on CX3CL1/CX3CR1 axis-stimulated nuclear factor- $\kappa B$ (NF- $\kappa$ B) signaling pathway. (A) IHC analysis of CX3CL1,

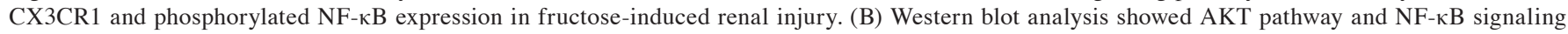
pathway activation. Data are expressed as the mean \pm SEM. ${ }^{\#} \mathrm{P}<0.05,{ }^{\# \#} \mathrm{P}<0.01$ and ${ }^{\# \#} \mathrm{P}<0.001$ vs. WT; ${ }^{*} \mathrm{P}<0.05,{ }^{* *} \mathrm{P}<0.01$ and ${ }^{* * *} \mathrm{P}<0.001$ vs. Fru-WT.

reported the increase of $\mathrm{NF}-\kappa \mathrm{B}$ pathway phosphorylation leads to inflammatory responses and cytokines production. Researchers have indicated that the activation of CX3CL1/ CX3CR1 axis was associated with AKT pathway (ref. ?). Thus, we further assessed the relationship of AKT pathway and CX3CL1/CX3CR1 axis. The data demonstrated that fructose administration has the ability to activate AKT pathway and increase the levels of phosphorylated AKT expression. Phosphorylated AKT expression could significantly enhance the activation of CX3CL1/CX3CR1 pathway and increase the $\mathrm{NF}-\kappa \mathrm{B}$ pathway activation.

To study the possible role of CX3CL1/CX3CR1 axis in fructose-induced kidney injury of mice, we used CX3CR1knock out mice as model to investigate the effects of crosstalk of CX3CL1-CX3CR1 axis and NF- $\mathrm{B}$ pathways. IHC analysis of $\mathrm{I} \kappa \mathrm{B}$ of fructose administration showed that $\mathrm{I} \kappa \mathrm{B}$ was involved in the development of renal injury. Compared with WT group, the $\mathrm{CX} 3 \mathrm{CR} 1^{-/-}$mice have a lower I $\mathrm{B}$ activation when challenged with fructose. As the inducer of CX3CR1, we tested the CX3CL1 expression between WT and CX3CR1 ${ }^{-1-}$ mice by IHC. The results indicated that CX3CR1 knockout directly impacts the expression of CX3CL1. The AKT signaling pathway may directly or indirectly associate with fructose-induced kidney injury. In knockout mice, the p-AKT expression was determined to be involved in the process of injury. The data indicated AKT as an important upstream of CX3CL1-CX3CR1 axis may impact CX3CL1-mediated inflammatory responses. 
A

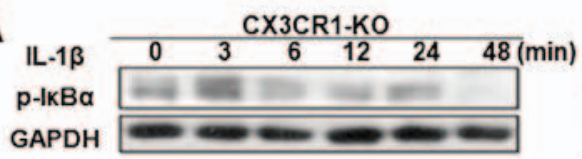

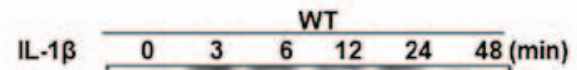

GAPDH
p-IKBa
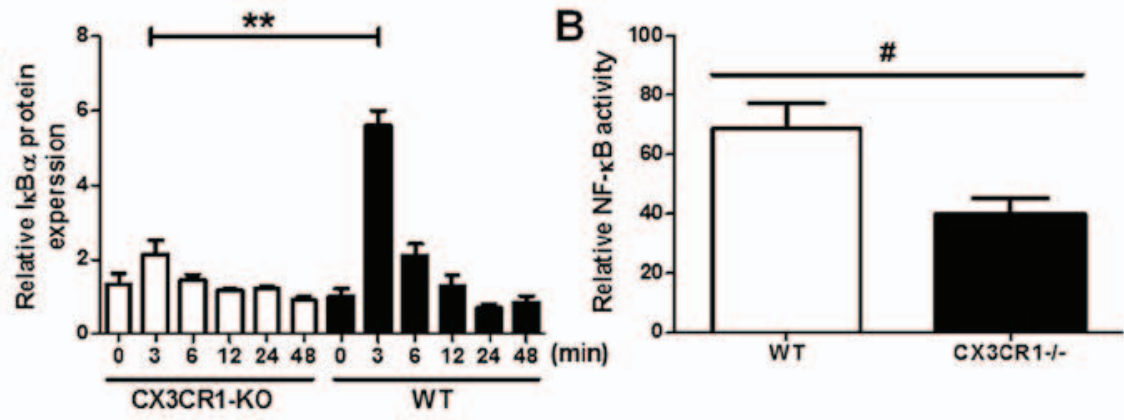

C
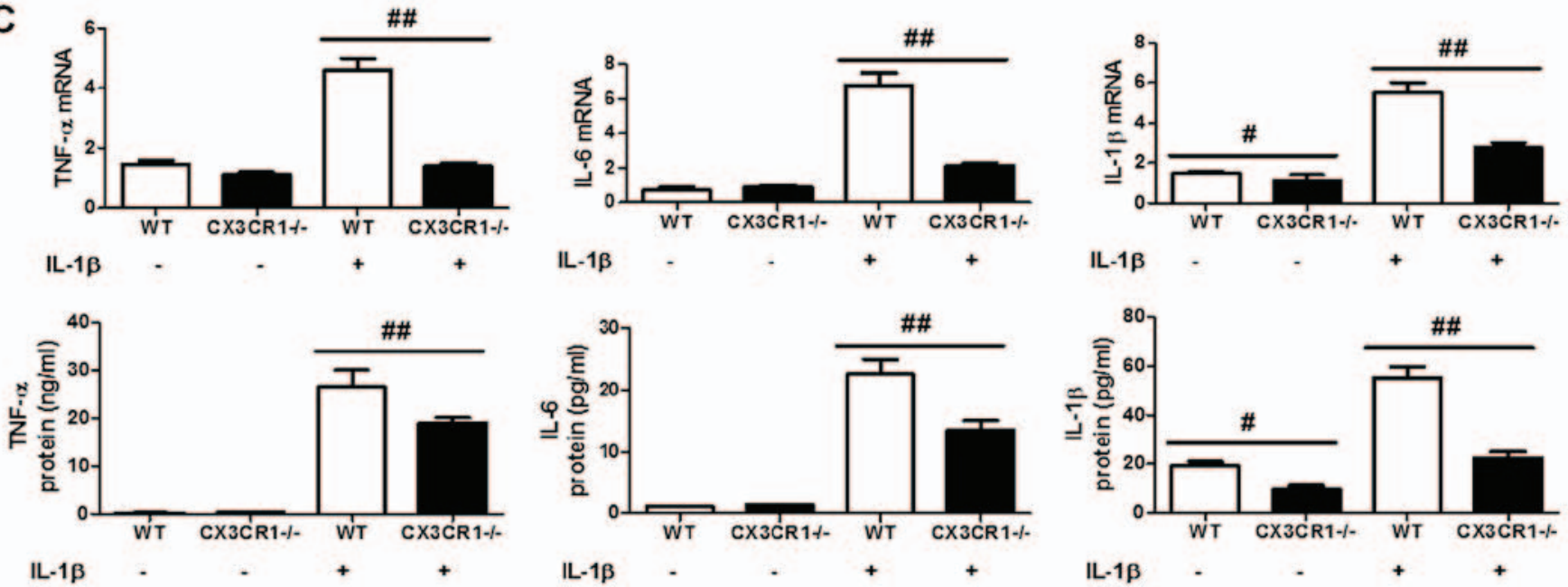

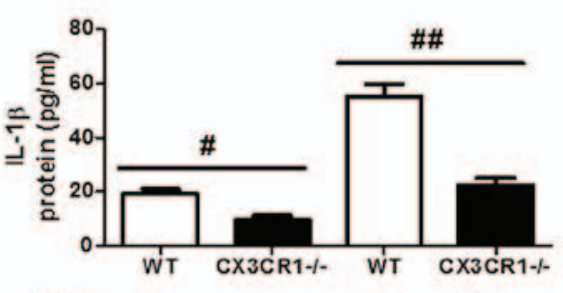

IL-1 $\beta$
D

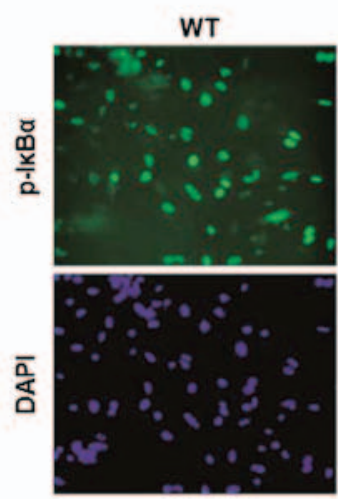

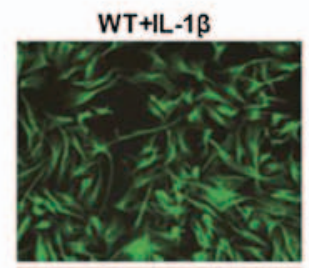

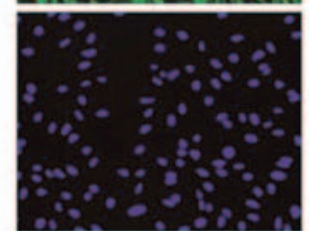

\section{CX3CR1-KO+IL-1B}
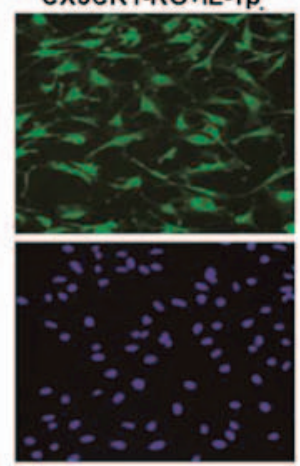

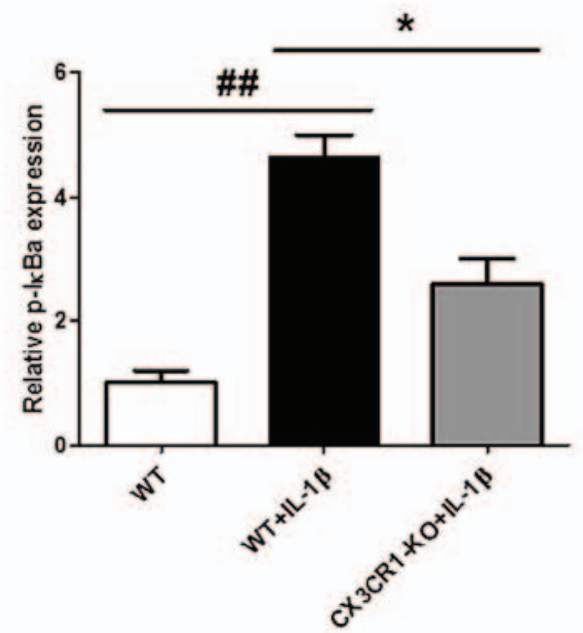

Figure 5. CX3CR1 deficiency inhibits inflammatory response through nuclear factor- $\mathrm{B}$ (NF- $\mathrm{kB}$ ) pathway in podocyte cells. (A) Western blot analysis for the

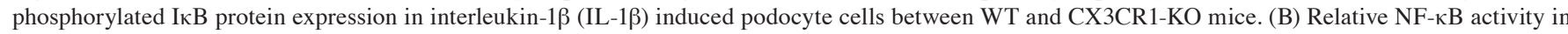
WT and CX3CR1-KO mice. (C) Enzyme-linked immunosorbent assay (ELISA) and qPCR analysis for the inflammatory cytokines expression in IL-1 $\beta$-induced cells between WT and CX3CR1-KO mice. (D) IHC analysis for the phosphorylated IкB protein expression in IL-1 $\beta$ induced podocyte cells between WT and CX3CR1-KO mice. Data are expressed as the mean \pm SEM. ${ }^{*} \mathrm{P}<0.05,{ }^{* *} \mathrm{P}<0.01$ and ${ }^{* * *} \mathrm{P}<0.001$ vs. CX3CR1-KO mice; ${ }^{*} \mathrm{P}<0.05,{ }^{\# \#} \mathrm{P}<0.01$ and ${ }^{\# \# \#} \mathrm{P}<0.001$ vs. WT.

We investigated fructose-induced kidney injury model from the point of CX3CL1-CX3CR1 axis and its-related indicators. We found that fructose as functional food additive has the ability to cause inflammation by enhancing CX3CL1-CX3CR1 axis and NF- $\kappa \mathrm{B}$ activation. Also, the phosphorylated AKT could be significantly activated in fructose-induced renal injury via CX3CL1-CX3CR1 axis. We further investigated the role of CX3CL1-CX3CR1 pathway in lung injury. CX3CR1 expression between WT and CX3CR $1^{-1-}$ mice were tested to establish their relationship to injury. Our results indicated that CX3CR1 may be the central and major indicator in the process of kidney injury, which mediate the CX3CL1 to activate AKT pathway and further enhance the NF- $\kappa \mathrm{B}$ activation.

\section{Competing interests}

Authors declare that they have no competing interest. 


\section{References}

1. Megyesi J, Andrade L, Vieira JM Jr, Safirstein RL and Price PM: Coordination of the cell cycle is an important determinant of the syndrome of acute renal failure. Am J Physiol Renal Physiol 283: F810-F816, 2002.

2. Zhou H, Kato A, Yasuda H, Miyaji T, Fujigaki Y, Yamamoto T, Yonemura $\mathrm{K}$ and Hishida $\mathrm{A}$ : The induction of cell cycle regulatory and DNA repair proteins in cisplatin-induced acute renal failure. Toxicol Appl Pharmacol 200: 111-120, 2004.

3. Price PM, Safirstein RL and Megyesi J: Protection of renal cells from cisplatin toxicity by cell cycle inhibitors. Am J Physiol Renal Physiol 286: F378-F384, 2004.

4. Megyesi J, Safirstein RL and Price PM: Induction of p21WAF1/ CIP1/SDI1 in kidney tubule cells affects the course of cisplatininduced acute renal failure. J Clin Invest 101: 777-782, 1998.

5. Zhou H, Fujigaki Y, Kato A, Miyaji T, Yasuda H, Tsuji T, Yamamoto T, Yonemura K and Hishida A: Inhibition of p21 modifies the response of cortical proximal tubules to cisplatin in rats. Am J Physiol Renal Physiol 291: F225-F235, 2006.

6. Nowak G, Price PM and Schnellmann RG: Lack of a functional p21WAF1/CIP1 gene accelerates caspase-independent apoptosis induced by cisplatin in renal cells. Am J Physiol Renal Physiol 285: F440-F450, 2003.

7. Nath KA: Provenance of the protective property of p21. Am J Physiol Renal Physiol 289: F512-F513, 2005.

8. Hengst L and Reed SI: Inhibitors of the Cip/Kip family. Curr Top Microbiol Immunol 227: 25-41, 1998.

9. Sherr CJ and Roberts JM: Inhibitors of mammalian G1 cyclin-dependent kinases. Genes Dev 9: 1149-1163, 1995.

10. Al-Mohanna MA, Manogaran PS, Al-Mukhalafi Z, A Al-Hussein K and Aboussekhra A: The tumor suppressor p16(INK4a) gene is a regulator of apoptosis induced by ultraviolet light and cisplatin. Oncogene 23: 201-212, 2004.

11. Le HV, Minn AJ and Massagué J: Cyclin-dependent kinase inhibitors uncouple cell cycle progression from mitochondrial apoptotic functions in DNA-damaged cancer cells. J Biol Chem 280: 32018-32025, 2005.
12. Mori K: Tripartite management of unfolded proteins in the endoplasmic reticulum. Cell 101: 451-454, 2000.

13. Kleizen B and Braakman I: Protein folding and quality control in the endoplasmic reticulum. Curr Opin Cell Biol 16: 343-349, 2004.

14. Szegezdi E, Logue SE, Gorman AM and Samali A: Mediators of endoplasmic reticulum stress-induced apoptosis. EMBO Rep 7: 880-885, 2006.

15. Price PM, Yu F, Kaldis P, Aleem E, Nowak G, Safirstein RL and Megyesi J: Dependence of cisplatin-induced cell death in vitro and in vivo on cyclin-dependent kinase 2. J Am Soc Nephrol 17: 2434-2442, 2006.

16. Yu F, Megyesi J and Price PM: Cytoplasmic initiation of cisplatin cytotoxicity. Am J Physiol Renal Physiol 295: F44-F52, 2008.

17. Hirai H, Roussel MF, Kato JY, Ashmun RA and Sherr CJ: Novel INK4 proteins, p19 and p18, are specific inhibitors of the cyclin D-dependent kinases CDK4 and CDK6. Mol Cell Biol 15: 2672-2681, 1995 .

18. Cordon-Cardo C: Mutations of cell cycle regulators. Biological and clinical implications for human neoplasia. Am J Pathol 147: 545-560, 1995.

19. Shankland SJ and Wolf G: Cell cycle regulatory proteins in renal disease: Role in hypertrophy, proliferation, and apoptosis. Am J Physiol Renal Physiol 278: F515-F529, 2000.

20. Franklin DS, Godfrey VL, Lee H, Kovalev GI, Schoonhoven R, Chen-Kiang S, Su L and Xiong Y: CDK inhibitors p18(INK4c) and p27(Kip1) mediate two separate pathways to collaboratively suppress pituitary tumorigenesis. Genes Dev 12: 2899-2911, 1998.

21. Wang D and Lippard SJ: Cellular processing of platinum anticancer drugs. Nat Rev Drug Discov 4: 307-320, 2005.

This work is licensed under a Creative Commons Attribution-NonCommercial-NoDerivatives 4.0 International (CC BY-NC-ND 4.0) License. 